05

\title{
Управление магнитными свойствами многослойных периодических структур на основе Co/Pt
}

\author{
(ㄱ Д.А. Татарский, ${ }^{1,2}$ Н.С. Гусев, ${ }^{1}$ В.Ю. Михайловский, ${ }^{3}$ Ю.В. Петров, ${ }^{3}$ С.А. Гусев ${ }^{1}$ \\ ${ }^{1}$ Институт фоизики микроструктур РАН, \\ 603087 Афонино, Нижегородская обл., Россия \\ ${ }^{2}$ Нижегородский государственный университет им. Н.И. Лобачевского, \\ 603950 Нижний Новгород, Россия \\ ${ }^{3}$ Санкт-Петербургский государственный университет, \\ 198504 Петергоф, Санкт-Петербург, Россия \\ e-mail: tatarsky@ipmras.ru
}

Поступило в Редакцию 28 марта 2019 г.

В окончательной редакции 28 марта 2019 г.

Принято к публикации 15 апреля 2019 г.

Исследована возможность управления магнитными свойствами многослойных периодических структур с перпендикулярной магнитной анизотропией на основе пленок кобальта и платины. Многослойные пленки, состоящие из слоев толщиной $0.5-1.0 \mathrm{~nm}$, подвергались двум типам воздействий: вакуумному отжигу при различных температурах и облучению пучками ионов гелия. Методами просвечивающей электронной микроскопии показано, что облучение ионами $\mathrm{He}^{+}$с энергией $30 \mathrm{keV}$ приводит к перемешиванию материала слоев, тогда как при вакуумном отжиге слоевая структура пленки сохраняется. При этом в результате термического отжига значительно увеличивается коэрцитивная сила структуры, а при облучении ионами гелия коэрцитивность пленок уменьшается вплоть до изменения типа анизотропии с перпендикулярной на анизотропию „легкая плоскость“.

Ключевые слова: кобальт, платина, перпендикулярная магнитная анизотропия, вакуумный отжиг, облучение, гелий.

DOI: 10.21883/JTF.2019.11.48327.135-19

\section{Введение}

Многослойные структуры на основе тонких слоев кобальта и платины обладают перпендикулярной магнитной анизотропией [1] и являются одним из перспективных материалов для использования в системах энергонезависимой магнитной память [2-4]. Особый интерес представляет исследование возможности изменения магнитных свойств таких пленок с помощью различных методов, влияющих на микрокристаллическую структуру, которая является одним из важнейших факторов, определяющих магнитные характеристики материалов $[5,6]$.

Так, в работах [7-12] исследовалось влияние облучения ферромагнитных пленок различными ионами на их магнитные свойства. Достаточно часто для изменения свойств металлических структур используют ионы $\mathrm{He}^{+}$, которые из-за разницы атомных масс с металлами обладают относительно небольшим коэффициентом распыления, что позволяет модифицировать структуру и свойства пленок, не нарушая их топографию. Это качество имеет важное значение для практического применения модифицированных пленок в системах магнитной записи. Хорошо известно, что облучение ионами гелия многослойных пленок с перпендикулярной анизотропией уменьшает их коэрцитивность, величину анизотропии, а при флюенсах $\mathrm{He}^{+}$более $10^{16} \mathrm{~cm}^{-2}$ (эта величина зависит от соотношения толщин слоев кобальта и платины) периодические структуры $\mathrm{Co} / \mathrm{Pt}$ могут стать парамагнитными $[13,14]$. Прежде всего, это связывают с разрушением интерфейсов между кобальтом и платиной и перемешиванием материала слоев. С другой стороны также известно, что возможно и увеличение коэрцитивности подобных структур с помощью термического отжига [15-22]. При этом во всех работах отмечено, что в зависимости от температуры отжига коэрцитивность сначала растет, но при температуре отжига более $300-400^{\circ} \mathrm{C}$ резко уменьшается. Одной из наиболее вероятных причин такого поведения магнитных характеристик может являться изменение размера кристаллического зерна пленок. При характерных размерах кристаллитов магнитные свойства тонкой пленки могут быть описаны в рамках слабой случайной магнитной анизотропии, когда коэрцитивная сила структуры ведет себя аналогичным немонотонным образом с ростом размера кристаллического зерна [6].

Цель настоящей работы заключается в исследовании возможности постростового изменения магнитных характеристик сформированных пленок, свойства которых позволят нам создавать структуры с неоднородными распределениями намагниченности типа магнитных „пузырей“ или магнитных вихрей (скирмионо-подобные состояния), и управлять размерами и плотностью этих неоднородных состояний. В частности, здесь приводятся результаты экспериментального исследования связи 
между изменениями магнитных свойств и определяющими их изменениями кристаллической структуры многослойных периодических пленок $\mathrm{Co} / \mathrm{Pt}$, полученных в ИФМ РАН и подвергшихся вакуумному отжигу или облучению ионами гелия.

\section{Подготовка образцов}

Магнитные структуры были изготовлены при помощи магнетронного напыления в атмосфере аргона $4 \cdot 10^{-2} \mathrm{~Pa}$. Предварительная откачка осуществлялась до $10^{-2} \mathrm{~Pa}$. В качестве подложек использовался монокристаллический кремний (100) со слоем естественного окисла и аморфные мембраны нитрида кремния $\mathrm{Si}_{3} \mathrm{~N}_{4}$ толщиной $50 \mathrm{~nm}$. Предварительно на подложку наносились буферные слои тантала и платины по 5-10 nm. Напыление происходило с отдельных мишеней Та, Со и $\mathrm{Pt}$ при комнатной температуре. Контроль толщин осуществлялся при помощи предварительной калибровки толщин отдельных слоев, близких к рабочим, методом рентгеновской рефлектометрии. Разброс скоростей напыления составлял от 0.1 (кобальт) до $0.3 \mathrm{~nm} / \mathrm{s}$ (платина). Толщина слоев кобальта составляла $0.5 \mathrm{~nm}$, толщина слоев платины $1.0 \mathrm{~nm}$. При этом выращивались структуры, содержащие три, четыре или пять периодов типа $(\mathrm{Co}(0.5 \mathrm{~nm}) / \mathrm{Pt}(1.0 \mathrm{~nm}))$. На полученную периодическую структуру сверху дополнительно наносился слой платины толщиной 2-5 nm для защиты от окисления.

Отжиг структур проходил при температурах 100, 200,300 и $400^{\circ} \mathrm{C}$ в вакуумной камере с постоянной откачкой при остаточном давлении не хуже $10^{-3} \mathrm{~Pa}$ в течение $2 \mathrm{~h}$. Выход на рабочую температуру занимал $1 \mathrm{~h}$, остывание до комнатной температуры - $2 \mathrm{~h}$. Контроль температуры осуществлялся при помощи термопары хромель-алюмель, расположенной непосредственно в месте крепления образца.

Облучение пучками ионов гелия $\mathrm{He}^{+}$с энергией $30 \mathrm{keV}$ производилось на гелиевом сканирующем ионном микроскопе Carl Zeiss ORION Nanofab. Структурные исследования методами просвечивающей электронной микроскопии проводились на микроскопе Carl Zeiss LIBRA 200MC.

Из образцов на кремниевых подложках с помощью двулучевого микроскопа Carl Zeiss Merlin с фокусированными пучками ионов $\mathrm{Ga}^{+} 30 \mathrm{keV}$ получали ламели с поперечными сечениями многослойных структур. Так как при такой подготовке в структурах возникает аморфный нарушенный слой, все ламели дополнительно подвергались полировке ионами $\mathrm{Ar}^{+}$с энергиями $300-500 \mathrm{eV}$. Такая методика прецизионной полировки позволяет с помощью методов просвечивающей электронной микроскопии разрешить тонкие слои кобальта и платины в многослойной структуре.

Образец для исследования влияния флюенса ионов гелия на структуру слоев кобальта и платины подготавливался следующим образом. Несколько образцов

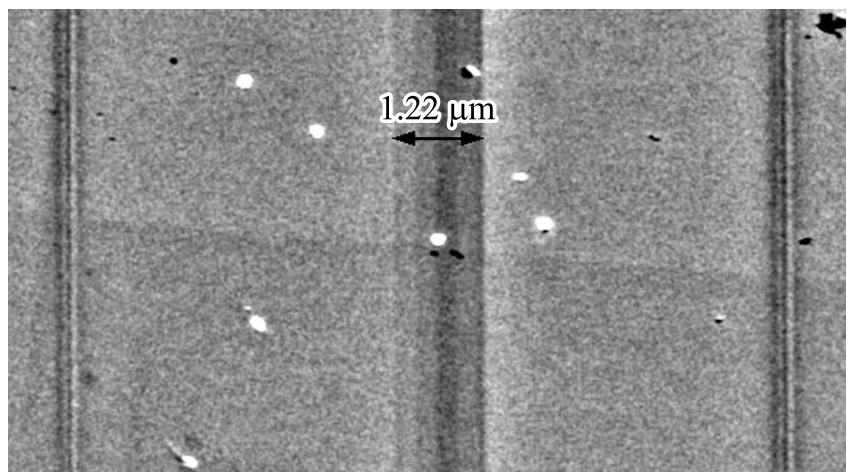

Рис. 1. Микрофотография в растровой электронной микроскопии структуры $\mathrm{Co} / \mathrm{Pt}$, локально облученной различными флюенсами ионов гелия $30 \mathrm{keV}$.

подвергались сплошному облучению ионами гелия с энергией $30 \mathrm{keV}$ для последующего измерения магнитооптических свойств. Для исследования влияния облучения на структуру пленки образец $\mathrm{Co} / \mathrm{Pt}$ на подложке кремния подвергался локальному воздействию фокусированных пучков ионов гелия. Облучение происходило вдоль параллельных линий, каждая с разной величиной флюенса. Всего было сформировано пять полос шириной $0.3 \mu \mathrm{m}$ (рис. 1). Такая схема облучения за счет материального контраста во вторичных электронах позволяет различить облученные области в растровом электронном микроскопе и прецизионно подготовить поперечный срез, содержащий все четыре модифицированные ионами области пленки на одном образце.

Облученные структуры на мембранах нитрида кремния были использованы для получения структурной информации с помощью электронно-микроскопических светло- и темнопольных микрофотографий и картин микродифракции. При этом темнопольные микрофотографии получены при различных положениях объективной диафрагмы, что позволяет получать изображения кристаллитов с различной ориентацией. Магнитные свойства образцов исследовались с помощью магнитооптического эффекта Керра на лазерном стенде.

\section{Результаты и их обсуждение}

Характерные магнитополевые зависимости относительной намагниченности структур $\mathrm{Co} / \mathrm{Pt}$, подвергавшихся термической обработке, приведены на рис. 2. Как показали магнитооптические измерения, с ростом температуры отжига коэрцитивность пленок при намагничивании в направлении легкой оси (перпендикулярно плоскости) сначала возрастает в несколько раз с 200 до 1000 Ое. Однако при отжиге с температурой выше $300^{\circ} \mathrm{C}$, ширина гистерезисной петли перемагничивания уменьшается. При дальнейшем отжиге в $400^{\circ} \mathrm{C}$ в пленках полностью пропадает перпендикулярная магнитная анизотропия. 


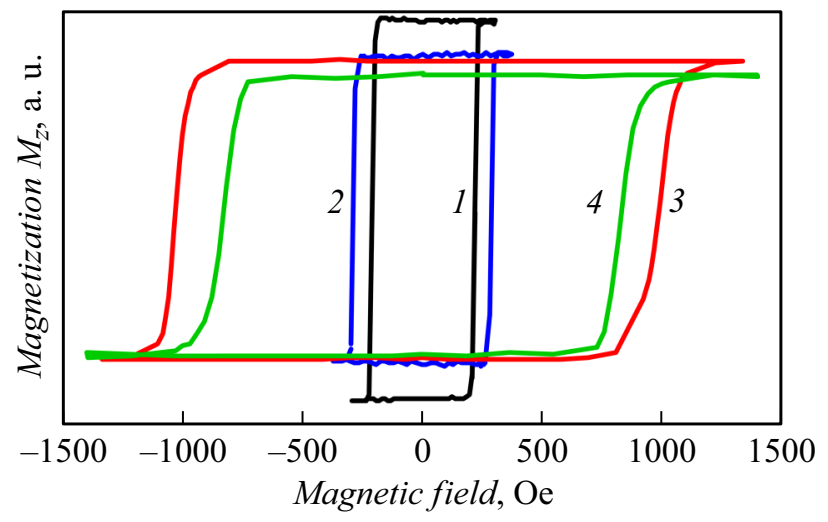

Рис. 2. Петли пермагничивания при отжиге многослойных пленок $\mathrm{Ta} / \mathrm{Pt} /(\mathrm{Co} / \mathrm{Pt}) \times 3.1-$ исходный образец, $2-$ отжиг при $100^{\circ} \mathrm{C}, 3$ - отжиг при $200^{\circ} \mathrm{C}$ и 4 - отжиг при $300^{\circ} \mathrm{C}$.

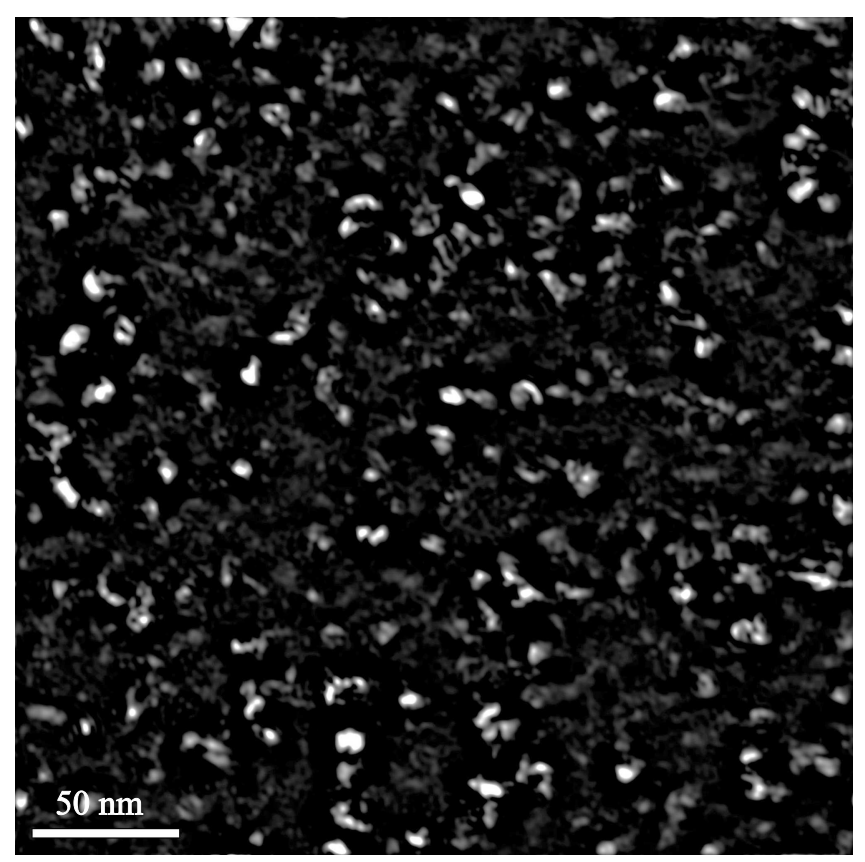

Рис. 3. Темнопольные электронные микрофотографии многослойной пленки $\mathrm{Co} / \mathrm{Pt}$ после отжига $400^{\circ} \mathrm{C}$. Светлые области соответствуют областям когерентного рассеяния электронов (кристаллитам).

На темнопольных электронно-микроскопических микрофотографиях образцов видно (рис. 3), что температурный отжиг ведет к увеличению размеров кристаллитов. Распределения по размерам кристаллитов пленок до и после отжига приведены на рис. 4. После отжига при температуре $400^{\circ} \mathrm{C}$ средний размер областей когерентного рассеяния увеличивается с 5.5 до $6.5 \mathrm{~nm}$. При этом на микрофотографиях поперечных срезов (рис. 5) видно, что вакуумный отжиг при температуре $200^{\circ} \mathrm{C}$ не приводит к перемешиванию слоев кобальта и платины. Слоистое строение пленки Сo/Pt наблюдалось и на поперечных срезах структуры после отжига при температуре $300^{\circ} \mathrm{C}$. После отжига при температуре $400^{\circ} \mathrm{C}$ качественные изображения поперечных срезов образцов получить не удалось, но опираясь на данные магнитооптических измерений, можно предположить, что при этом произошло перемешивание материала слоев с образованием твердого раствора $\mathrm{CoPt}$, что и явилось причиной исчезновения перпендикулярной магнитной анизотропии.

Микродифракционные изображения пленок исходной структуры соответствуют кубической гранецентрированной решетке $F m 3 m$ с параметром $a=0.390 \pm 0.008 \mathrm{~nm}$. Это значение лежит между величиной параметра решетки платины $a_{\mathrm{Pt}}=0.392 \mathrm{~nm}$ и кубической решетки твердого раствора $\mathrm{CoPt} a_{\mathrm{CoPt}}=0.384 \mathrm{~nm}$, что показывает наличие упругих напряжений в многослойной структуре. После отжига при температуре $400^{\circ} \mathrm{C}$ на микродифрактограммах также проявляются точечные рефлексы, соответствующие объемно центрированной решетке пленки тантала (рис. $6, a$ ), которая на исходной пленке не дает однозначно идентифицируемых отражений. Необходимо отметить, что соотношение интен-

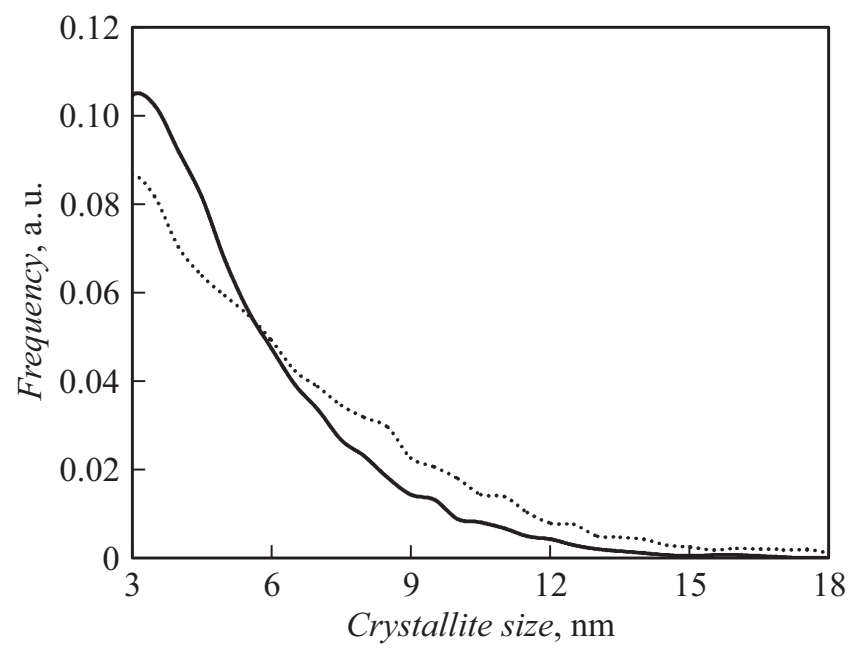

Рис. 4. Распределение кристаллитов по размерам. Сплошная линия - исходный образец, пунктирная - образец после отжига $400^{\circ} \mathrm{C}$.

\section{Initial $200^{\circ} \mathrm{C}$}

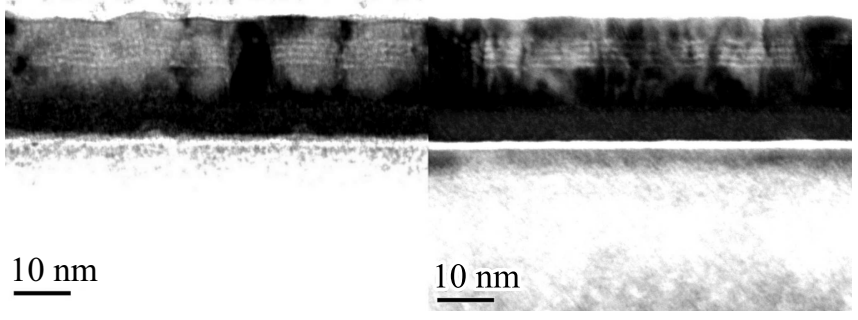

Рис. 5. Светлопольные микрофотографии поперечных срезов исходной пленки $[\mathrm{Co}(0.5 \mathrm{~nm}) / \mathrm{Pt}(1.0 \mathrm{~nm})] \times 4(a)$ и отожженной при $200^{\circ} \mathrm{C}(b)$, на обеих микрофотографиях хорошо различимы слои Со и $\mathrm{Pt}$. 
$a$
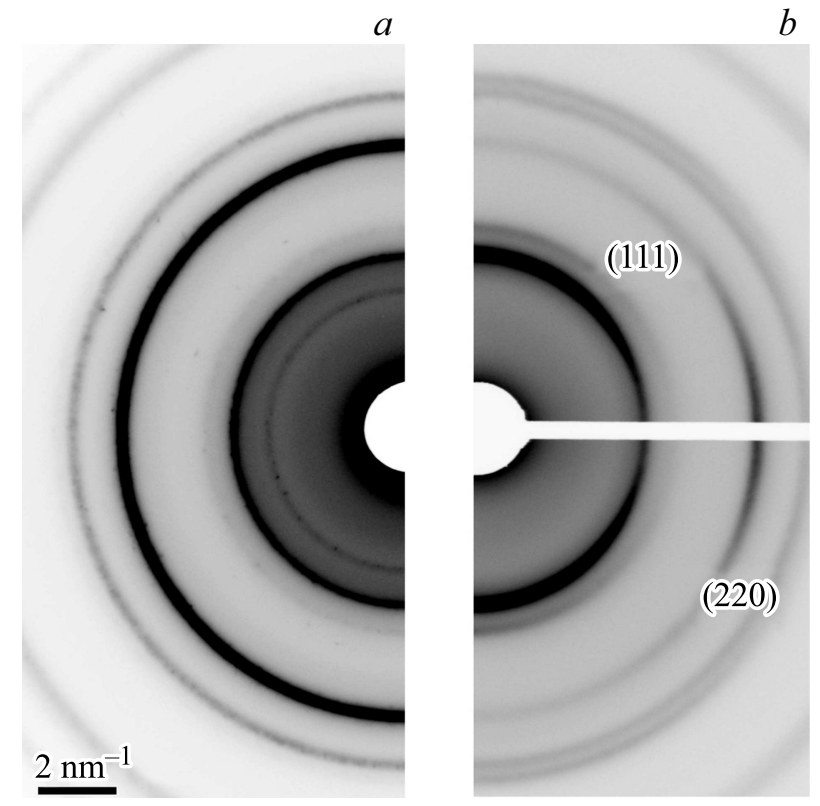

Pис. 6. Электронная микродифракция на отожженной при $400^{\circ} \mathrm{C}$ пленке $(a)$ и исходной пленке при наклоне образца на $20^{\circ}$ для определения текстуры $(b)$.

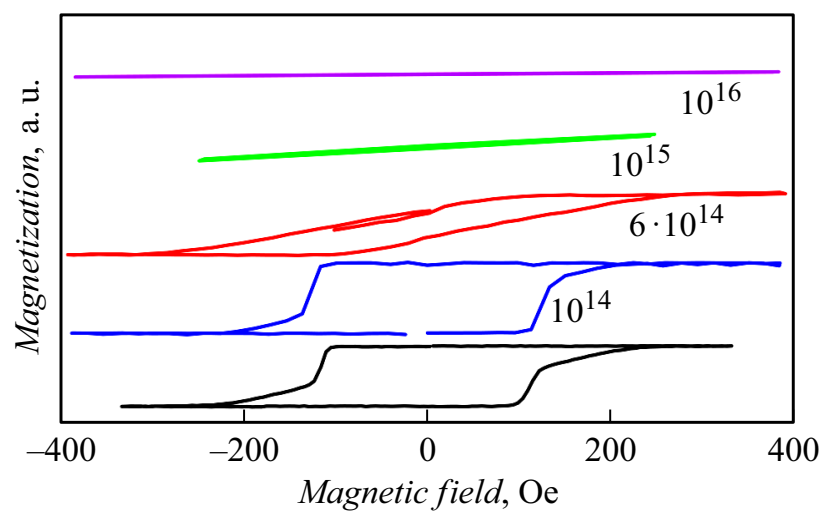

Рис. 7. Петли перемагничивания пленок $[\mathrm{Co}(0.5 \mathrm{~nm}) / \mathrm{Pt}(1.0 \mathrm{~nm})] \times 5$ с различной дозой облучения ионами гелия. Дозы в ions $/ \mathrm{cm}^{2}$ подписаны на рисунке.

сивностей дифракционных колец говорит о наличии у многослойной магнитной пленки осевой текстуры. Так, при нормальном падении электронов на образец интенсивность дифракционного отражения (220) существенно больше интенсивности (111). При наклонной геометрии получения микродифракционных изображений (рис. $6, b$ ) сплошные кольца структуры $\mathrm{Co} / \mathrm{Pt}$ превращались в дуги, и возрастала интенсивность отражений (111), что свидетельствовало о наличии в исходном и в термически обработанном образцах слабой осевой текстуры с ориентацией [111], перпендикулярной плоскости пленки.

Результаты измерений магнитооптических характеристик образцов, подвергшихся облучению ионами гелия, для нескольких флюенсов приведены на рис. 7. Исходная пленка при намагничивании вдоль легкой оси (перпендикулярно плоскости) имела характерную для структур с перпендикулярной анизотропией петлю гистерезиса с коэрцитивностью около 200 Ое. При облучении ионами $\mathrm{He}^{+}$с энергией $30 \mathrm{keV}$ мы наблюдаем с ростом флюенса (варьировался от $\sim 10^{14}$ до $10^{16} \mathrm{~cm}^{-2}$ ) как уменьшение перпендикулярной магнитной анизотропии и коэрцитивности структур, так и смену типа анизотропии на легкую плоскость при больших дозах облучения. Для выяснения происходящих при таком облучении процессов в многослойной структуре было выполнено моделирование с помощью программного пакета SRIM [23]. Из-за малой массы по сравнению с атомами металлов ионы гелия обладают большой проникающей способностью и основную часть энергии теряют в подложке. Поэтому в данном случае основные структурные изменения металлической пленки происходят не из-за локального разогрева, а вследствие радиационных повреждений, которые вызваны прямым выбиванием атомов из занимаемых положений. Моделирование показывает, что при наших экспериментальных условиях средняя длина смещения атома кобальта в слое платины при попадании в него иона гелия составляет около $0.4 \mathrm{~nm}$, а для атома платины в слое кобальта эта величина составляет около $0.5 \mathrm{~nm}$. Таким образом, происходит перемешивание слоев кобальта и платины, что приводит к увеличению шероховатости поверхности раздела пленок. Численная оценка также показывает, что концентрация атомов платины в слое кобальта после ионного облучения $\mathrm{He}^{+}$с энергией $30 \mathrm{keV}$ изменяется от 3.3 до $65 \%$ при изменении плотности потока ионов от $5 \cdot 10^{14}$ до $10^{16} \mathrm{~cm}^{-2}$. При таких концентрациях среднее расстояние между атомами платины, внедренными в слой кобальта, изменяется от 1.60 до $0.36 \mathrm{~nm}$. Следовательно, в случае сильного флюенса вместо сплошного слоя кобальта мы получаем пленку из атомов кобальта, окруженных атомами платины. В то же время слои платины выше и ниже слоя кобальта содержат внедренные атомы кобальта с концентрацией до $13 \%$. Таким образом, вместо сплошных плоских слоев мы в результате облучения получаем многослойную структуру из гофрированных пленок с размытыми границами и периодически переменной концентрацией металлов. Увеличение шероховатости поверхности раздела пленок и взаимное перемешивание материалов приводит к уменьшению перпендикулярной магнитной анизотропии вплоть до смены ее на анизотропию ,легкая плоскость“.

Экспериментальные исследования структурных изменений многослойных пленок $\mathrm{Co} / \mathrm{Pt}$ при ионном облучении находятся в хорошем соответствии с результатами моделирования. Электронно-микроскопические изображения поперечного сечения исходной и облученной $\mathrm{Co} / \mathrm{Pt}$ с флюенсом $10^{16} \mathrm{~cm}^{-2}$ приведены на рис. $8, a, b$. На рис. 8,c приведено усредненное распределение интенсивности на микрофотографиях поперек слоев структур, подвергшихся облучению разными дозами. Необходимо отметить, что, несмотря на сохранение периодичности, хорошо заметно снижение относительного кон- 

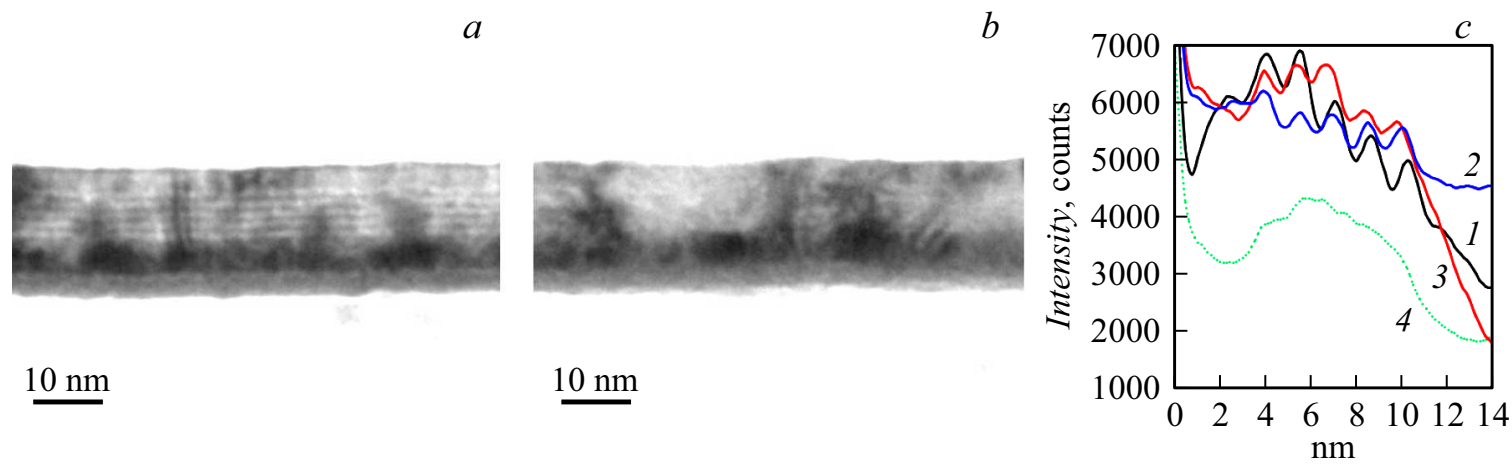

Рис. 8. Светлопольные микрофотографии поперечного среза пленки $[\operatorname{Co}(0.5 \mathrm{~nm}) / \mathrm{Pt}(1.0 \mathrm{~nm})] \times 5 . a-$ исходная пленка, $b-$ после облучения флюенсом $10^{16} \mathrm{~cm}^{-2}, c-$ сравнительный контраст в зависимости от флюенса: $1-$ исходная пленка, $2-10^{15}, 3-$ $5 \cdot 10^{15}, 4-10^{16} \mathrm{~cm}^{-2}$.

траста между изображениями слоев кобальта и платины при увеличении дозы облучения вплоть до исчезновения периодической модуляции при флюенсе $10^{16} \mathrm{~cm}^{-2}$. Стоит отметить также, что облучение ионами гелия приводит и к увеличению размера кристаллитов, но не такому заметному по сравнению с термическим отжигом.

\section{Заключение}

Таким образом, в работе продемонстрировано, что дополнительная технологическая обработка многослойных пленок $\mathrm{Co} / \mathrm{Pt}$ с перпендикулярной магнитной анизотропией, сформированных магнетронным распылением, позволяет в широких пределах управлять их магнитными свойствами, увеличивать или уменьшать величину коэрцитивности, изменять величину и тип магнитной анизотропии. Показано, что изменения магнитных характеристик пленок при термическом отжиге (с температурой менее $400^{\circ} \mathrm{C}$ ) и при ионном облучении имеют разнонаправленный характер и вызваны различными механизмами структурной модификации слоев. При термическом отжиге рост коэрцитивности многослойных пленок $\mathrm{Co} / \mathrm{Pt}$ связан, прежде всего, с увеличением среднего размера кристаллита, но не с перемешиванием слоев кобальта и платины. Облучение ионами гелия слабо влияет на размер кристаллитов, но приводит к сильному перемешиванию материала слоев кобальта и платины, тем самым снижая величину перпендикулярной магнитной анизотропии при малых дозах облучения, или смены ее типа на анизотропию „легкая плоскость“ при больших дозах облучения.

\section{Финансирование работы}

Работа выполнена при поддержке грантов РФФИ (получение и отжиг многослойных плёнок выполнен в рамках гранта № 18-02-00247; модификация ионами гелия и структурные исследования выполнены в рамках гранта № 18-02-00827). В работе использовано оборудование Междисциплинарного ресурсного центра по направлению „Нанотехнологии“ (СПбГУ) и ЦКП „Физика и технология микро- и наноструктур“ (ИФМ PAH).

\section{Конфликт интересов}

Авторы заявляют, что у них нет конфликта интересов.

\section{Список литературы}

[1] Carcia P.F. // J. Appl. Phys. 1988. Vol. 63. P. 5066-5073. DOI 10.1063/1.340404.

[2] Ziemys G., Ahrens V., Mendisch S., Csaba G., Becherer M. // AIP Advances 2018. Vol. 8. P. 056310-1-056310-6. DOI 10.1063/1.5007308.

[3] Becherera M., Kiermaiera J., Breitkreutza S., Eichwalda I., Žiemysa G. Csabab G., Schmitt-Landsiedela D. // Solid-State Electronics. 2014. Vol. 102. P. 46-51. DOI 10.1016/j.sse.2014.06.012

[4] Kiermaier J., Breitkreutz S., Eichwald I., Engelstädter M., Ju X., Csaba G., Schmitt-Landsiedel D., Becherer M. // J. Appl. Phys. 2013. Vol. 113. P. 17B902-1-17B902-3. DOI 10.1063/1.4794184

[5] R. Alben, J.J. Becker, M.C. Chi // J. Appl.Phys. 1978. Vol. 49. P. 1653-1658. DOI $10.1063 / 1.324881$

[6] Гусев С.А., Татарский Д.А., Климов А.Ю., Рогов В.В., Скороходов Е.В., Сапожнииков М.В., Грибков Б.А., Нефёдов И.М., Фраерман А.А. // ФТТ. 2013. Т. 55. С. 435-439. DOI 10.1134/S1063783413030141.

[7] Sapozhnikov M.V., Vdovichev S.N., Ermolaeva O.L., Gusev N.S., Fraerman A.A., Gusev S.A., Petrov Yu.V. // Appl. Phys. Lett. 2016. Vol. 109. P. 042406-1-042406-5. DOI $10.1063 / 1.4958300$.

[8] Gusev S.A., Drozdov M.N., Ermolaeva O.L., Fraerman A.A., Gusev N.S., Mikhailovskii V.Yu., Petrov Yu.V., Sapozhnikov M.V., Vdovichev S.N. // AIP Conf.Proc. 2016. Vol. 1748. P. 030002-1-030002-7. DOI 10.1063/1.4954348.

[9] Tatarskiy D.A., Skorokhodov E.V., Gusev N.S., Mikhailovskii V.Yu., Petrov Yu.V., Gusev S.A. // AIP Conf. Proc. 2019. Vol. 2064. P. 020005-1-020005-6. DOI 10.1063/1.5087661. 
[10] Aziz A., Bending S.J., Roberts H., Crampin S., Heard P.J., Marrows C.H. // J. Appl. Phys. 2005. Vol. 98. P. 124102-1124102-4. DOI 10.1063/1.2149500.

[11] Gupta R., Lieb K.P., Muller G.A., Weisheit M., Zhang K. // Nucl. Instr. Meth. Phys. Res. B. 2006. Vol. 2246. P. 393-396. DOI 10.1016/j.nimb.2006.01.019.

[12] Fassbender J., McCord J. // J. Magn. Magn. Mater. 2008. Vol. 320. P. 579-596. DOI 10.1016/j.jmmm.2007.07.032.

[13] Rettner C.T., Anders S., Baglin J.E. E., Thomson T., Terris B.D. // Appl. Phys. Lett. 2002. Vol. 80. P. 279-281. DOI 10.1063/1.1432108.

[14] Devolder T., Ferré J., Chappert C., Bernas H., Jamet J.-P., Mathet V. // Phys. Rev. B. 2001. Vol. 64. P. 064415-1-0644157. DOI 10.1103/PhysRevB.64.064415.

[15] Гусев С.А., Ноздрин Ю.Н., Розенштейн Д.Б., Целев А.Е. // ЖТФ. 1998. Т. 68. Вып. 4. C. 66-70. DOI 10.1134/1.1258995.

[16] Sehdev N., Medwal R., Malik R., Kandasami A., Kanjilald D., Annapoornie S. // Nucl. Instr. Meth. Phys. Res. B. 2018. Vol. 420. P. 50-56. DOI 10.1016/j.nimb.2018.02.003.

[17] Wang Yi., Wang W.X., Wei H.X., Zhang B.S., Zhan W.S., Han X.F. // J. Appl. Phys. 2010. Vol. 107. P. 09C711-1-09C711-3. DOI 10.1063/1.3358249

[18] Lee T.Y., Won Y.Ch., Su Son D., Ho Lim S., Lee S.-R. // J. Appl. Phys. 2013. Vol. 114. P. 173909-1-173909-6. DOI $10.1063 / 1.4829024$.

[19] Lee T.Y., Su Son D., Ho Lim S., Lee S.-R. // J. Appl. Phys. 2013. Vol. 113. P. 216102-1-216102-3. DOI $10.1063 / 1.4809130$.

[20] Hara R., Hayakawa K., Ebata K., Sugita R. // AIP Advances. 2016. Vol. 6. P. 056117-1-056117-7. DOI 10.1063/1.4943930

[21] Yamane H., Maeno Y., Kobayashi M. // Appl. Phys. Lett. 1993. Vol. 62. P. 1562-1564. DOI 10.1063/1.108641

[22] Zhihong J., Defang Sh., Tiansheng Shi, Changlin G., Rongfa G. // Chin. Phys. Lett. 1994. Vol. 11. P. 169-172. DOI 10.1088/0256-307X/11/3/011.

[23] Ziegler J.F., Ziegler M.D., Biersack J.P. // Nucl. Instr. Meth. Phys. Res. B. 2010. Vol. 268. P. 1818-1823.

DOI 10.1016/j.nimb.2010.02.091. 